\title{
Ventricular septal defect after myocardial infarction: assessment by cross sectional echocardiography with pulsed wave Doppler scanning
}

\author{
DONALD MACLEOD, LAMEH FANANAPAZIR, DAVID DE BONO, \\ PETER BLOOMFIELD \\ From the Department of Cardiology, Royal Infirmary, Edinburgh
}

SUMMARY Eight patients who developed a ventricular septal defect after myocardial infarction were assessed by cross sectional echocardiography and pulsed wave Doppler scanning. Cross sectional echocardiography visualised the defect in four patients and gave an accurate assessment of global and regional left ventricular function in all eight. In all patients pulsed wave Doppler scanning detected turbulent flow at the apex of the right ventricle or adjacent to a wall motion abnormality affecting the interventricular septum. Pulsed wave Doppler detected coexisting mitral regurgitation in one patient and tricuspid regurgitation in another two. In all patients a left to right shunt was confirmed by oximetry and the location of the defect was identified by angiography or at operation or necropsy.

Cross sectional echocardiography in combination with pulsed wave Doppler scanning is useful in the rapid bedside evaluation of patients with ventricular septal defect after myocardial infarction.

Rupture of the interventricular septum is a life threatening complication that occurs in $0.5-1.0 \%$ of patients with acute myocardial infarction. Typically, a patient presents with haemodynamic deterioration and the development of a pansystolic murmur, usually within a week of acute myocardial infarction. Early and accurate diagnosis, and in particular distinction from acute mitral regurgitation, is essential because an appropriate operation may be life saving. The diagnosis of septal rupture has usually been confirmed by demonstrating a left to right shunt with oximetry at Swan-Ganz catheterisation and by contrast ventriculography, but a reliable noninvasive bedside technique would be preferable. Cross sectional echocardiography can demonstrate the actual defect and the reliability of this technique may be enhanced by the injection of agitated saline into a peripheral or central vein to act as an echocardiographic contrast medium. ${ }^{1}$ Recently, pulsed wave Doppler scanning has been used to demon-

Requests for reprints to Dr Peter Bloomfield, Cardiac Department, Western General Hospital, Edinburgh EH4 2XU.

Accepted for publication 14 May 1987 strate abnormal intracardiac flow adjacent to the suspected defect. $^{2-4}$ We report our experience with combined cross sectional echocardiography and pulsed wave Doppler scanning in eight consecutive cases of postinfarction ventricular septal rupture.

\section{Patients and methods}

\section{PATIENTS}

Since March 1985 all patients in our coronary care unit or referred from outside hospitals with suspected ventricular septal rupture after myocardial infarction have had cross sectional echocardiographic studies with pulsed wave Doppler scanning. During this time we have studied eight patients with postinfarction ventricular septal defect confirmed by angiography or at operation or necropsy.

The table summarises the clinical details of the eight patients. Three patients had inferior and five had anterior myocardial infarction and all developed a pansystolic murmur. Patient 5 developed a $2 / 6$ pansystolic murmur ten days after anterior myocardial infarction and was thought both clinically and on the basis of cross sectional echocardiography with pulsed wave Doppler scanning to have devel- 
oped mild mitral regurgitation. She was discharged but six days later she was readmitted with pulmonary oedema and a $4 / 6$ pansystolic murmur. A ventricular septal defect and mitral regurgitation were found. Patient 8 first presented with dyspnoea but gave a history typical of myocardial infarction occurring two weeks previously.

\section{ECHOCARDIOGRAPHIC EXAMINATION}

Cross sectional echocardiography with pulsed wave Doppler scanning was performed with a HewlettPackard model No 77020A phased array echocardiograph and integral pulsed Doppler system. Seven of the eight patients were studied within 24 hours of the development of the murmur and in six cases this was before oximetry or contrast ventriculography. We attempted to record parasternal long and short axis views and apical two and four chamber views. In all views we attempted to visualise the ventricular septal defect directly, particularly in the four chamber and parasternal short axis views. The transducer was swept through an arc to image as much of the septal anatomy as possible. Global and regional left ventricular function was assessed from the cross sectional echocardiographic images. For pulsed wave Doppler analysis the sample volume was placed to interrogate the apex and body of both ventricles and also the atria to determine whether mitral or tricuspid regurgitation could be detected.

In all cases ventricular septal rupture was confirmed by oximetry or left ventricular angiography in the $45^{\circ}$ left anterior oblique projection or both. Anatomical confirmation was obtained in seven cases at operation or necropsy.

\section{Results}

\section{CROSS SECTIONAL ECHOCARDIOGRAPHY}

Wall motion abnormalities-Assessment of regional left ventricular wall motion abnormalities and global function by cross sectional echocardiography accorded with abnormalities demonstrated at angiography. The left ventricular apex was affected in all cases whether the electrocardiographic site of infarction was inferior or anterior.

Direct visualisation of the defect-In patients $1,2,3$, and 7 the defect could be seen clearly by cross sectional echocardiography in the apical four chamber and parasternal short axis views over the left ventricular apex. In one case (patient 3) the defect was shown to follow a serpentine course through the interventricular septum as the septum was imaged from apex to base, a finding that was confirmed at necropsy. In the remaining four cases (patients 4,5 , 6 , and 8) a defect in the septum could not be visualised clearly but the septum appeared thin and hypo-

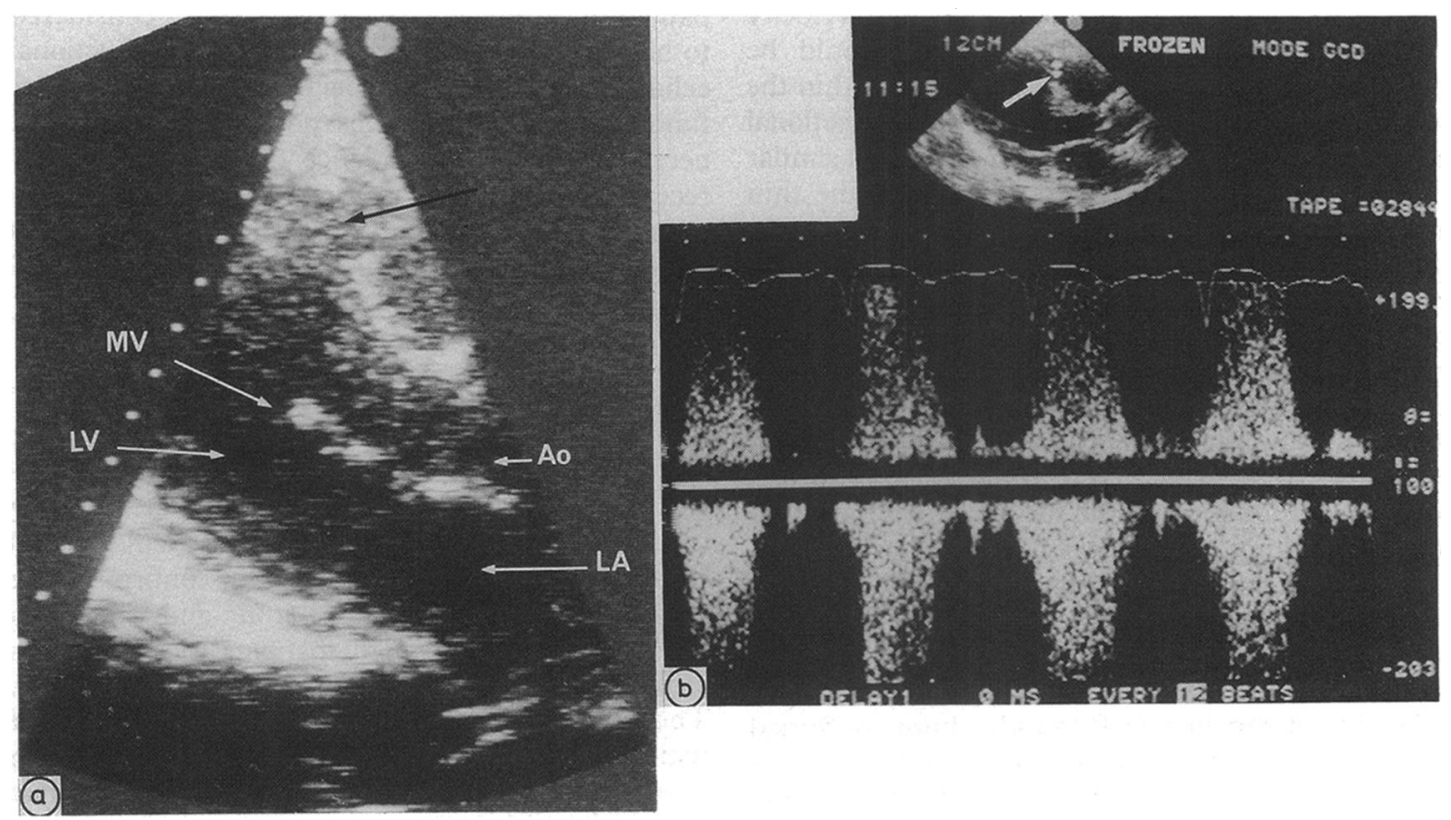

Fig Cross sectional echocardiogram (a) in the parasternal long axis view showing a probable defect in the interventricular septum (black arrow). (b) A similar view in another patient with the pulsed wave Doppler sample volume adjacent to the ventricular septal defect (arrow).. The Doppler signal shows turbulent flow with aliasing. $L V$, left ventricle; $L A$, left atrium; Ao, aortic root; $M V$, mitral valve. 
Table Clinical characteristics and outcome of eight patients with ventricular septal rupture after myocardial infarction

\begin{tabular}{|c|c|c|c|c|c|c|c|c|}
\hline \multirow[b]{2}{*}{ Patient } & \multirow[b]{2}{*}{$\begin{array}{l}\text { Age and } \\
\text { sex }\end{array}$} & \multirow[b]{2}{*}{$\begin{array}{l}E C G \text { site } \\
\text { of } M I\end{array}$} & \multicolumn{3}{|c|}{ Days after $M I$ : } & \multicolumn{2}{|c|}{ NYHA class: } & \multirow[b]{2}{*}{ Outcome } \\
\hline & & & $\begin{array}{l}\text { To } \\
\text { appearance } \\
\text { of murmur }\end{array}$ & $\begin{array}{l}\text { To } \\
\text { operation }\end{array}$ & $\begin{array}{l}\text { Auscultatory } \\
\text { findings }\end{array}$ & $\begin{array}{l}\text { At } \\
\text { echo }\end{array}$ & $\begin{array}{l}\text { At } \\
\text { operation }\end{array}$ & \\
\hline 1 & $69 \mathrm{~F}$ & Inferior & 4 & 4 & PSM 3/6 & IV & IV & Repair + CABG, \\
\hline $\begin{array}{l}2 \\
3\end{array}$ & $\begin{array}{l}77 \mathrm{M} \\
74 \mathrm{M}\end{array}$ & $\begin{array}{l}\text { Anterior } \\
\text { Inferior }\end{array}$ & $\begin{array}{l}4 \\
6\end{array}$ & $\stackrel{9}{\text { None }}$ & $\begin{array}{l}\text { PSM } 3 / 6 \\
\text { PSM } 3 / 6\end{array}$ & II & IV & $\begin{array}{l}\text { perioperative death } \\
\text { Repair + CABG } \\
\text { Death }\end{array}$ \\
\hline 4 & $69 M$ & Anterior & 6 & None & PSM 4/6 & IV & - & $\begin{array}{l}\text { Death (ventricular } \\
\text { fibrillation) }\end{array}$ \\
\hline $5^{\star}$ & $70 \mathrm{~F}$ & Anterior & $\begin{array}{l}10 \\
20\end{array}$ & 22 & $\begin{array}{l}\text { PSM 2/6 } \\
\text { PSM 4/6 }\end{array}$ & II & $\overline{I V}$ & $\begin{array}{c}\text { Repair MVR + AVR, } \\
\text { perioperative death }\end{array}$ \\
\hline $\begin{array}{l}6 \\
7 \\
8\end{array}$ & $\begin{array}{l}73 \mathrm{~F} \\
65 \mathrm{M} \\
71 \mathrm{M}\end{array}$ & $\begin{array}{l}\text { Anterior } \\
\text { Anterior } \\
\text { Inferior }\end{array}$ & $\begin{array}{l}2 \\
3 \\
\text { Presented }\end{array}$ & $\begin{array}{r}13 \\
3\end{array}$ & $\begin{array}{l}\text { PSM } 4 / 6 \\
\text { PSM } 3 / 6\end{array}$ & II & II & $\begin{array}{l}\text { Repair } \\
\text { Repair }\end{array}$ \\
\hline & & & at 14 days & 60 & PSM 3/6 & II & II & Repair + CABG \\
\hline
\end{tabular}

^Patient 5 had two examinations (see text).

MI, myocardial infarction; PSM, pansystolic murmur; NYHA, New York Heart Association; MVR, mitral valve replacement; AVR, aortic valve replacement; CABG, coronary artery bypass graft.

kinetic in the segment where the defect was demonstrated at angiography.

PULSED WAVE DOPPLER SCANNING

In patients $1,2,3$, and 7 when the sample volume was placed adjacent to the septal defect and within the right ventricle a harsh Doppler audio signal was recorded in systole. Spectral analysis of the signal demonstrated multiple frequencies and aliasing of the signal, indicating turbulent and high velocity flow (fig). In two cases these signals could be detected with the sample volume located within the ventricular septal defect seen on cross sectional echocardiography. In patients $4,5,6$, and 8 a similar Doppler signal was identified adjacent to the thin and akinetic segment of the interventricular septum (fig). In all cases the turbulent Doppler signal was clearly distinguishable from the normal laminar and biphasic flow pattern at the level of the tricuspid valve. Patients 2 and 6 had clinical evidence of tricuspid regurgitation and turbulent flow was detected within the right atrium by Doppler. Patient 5 had two studies: the first at 10 days demonstrated mitral regurgitation and the second, when there was a sudden clinical deterioration at 20 days, demonstrated both mitral regurgitation and a ventricular septal defect (table).

\section{INVASIVE STUDIES}

All eight patients had a left to right shunt confirmed by oximetry. Seven patients underwent contrast ventriculography which demonstrated the site of the defect. Of these, four had three vessel disease on coronary angiography and in all seven the artery supplying the territory of the myocardial infarction was occluded.

\section{PATHOLOGICAL EXAMINATION}

Six patients underwent surgical repair; four survived and two died perioperatively from pump failure. Patient 5 underwent repair of the ventricular septal defect and mitral valve replacement. Because the aortic valve was inadvertently damaged at operation this too was replaced (table). Two died within 48 hours of diagnosis, one suddenly from ventricular fibrillation and one in cardiogenic shock. The patient in cardiogenic shock (case 3) was considered to be inoperable on the basis of the cross sectional echocardiographic assessment of left ventricular function; angiography was not performed and at necropsy there was evidence of old anterior anc. recent inferoapical myocardial infarction with a sc pentine defect through the basal and apical segments of the ventricular septum.

\section{Discussion}

We have shown that cross sectional echocardiography with pulsed wave Doppler scanning can demonstrate the presence of ventricular septal rupture after myocardial infarction, confirming the previous reports of Miyatake et $\mathrm{al}^{2}$ and Cheesman et al. ${ }^{4}$ In four of our eight patients the defect was visualised by cross sectional echocardiography. There was good agreement in the assessment of regional and global left ventricular function between cross sectional echocardiography and contrast ventriculography.

On initial study one patient (patient 5) was thought to have only mitral regurgitation. At a later study a ventricular septal defect had developed. It is 
possible that a ventricular septal defect was present at the time of the first study, but the patient's rapid deterioration and new clinical and Doppler echocardiographic findings strongly suggest that septal rupture occurred after the first examination.

We believe that cross sectional echocardiography with pulsed wave Doppler scanning can provide diagnostic confirmation and important information about global and regional left ventricular function at the bedside in patients with a suspected ventricular septal defect after myocardial infarction. This technique may reduce the necessity for full angiographic assessment of such patients, especially when poor left ventricular function excludes surgical intervention. It is also possible that operation could be considered without angiography or after coronary angiography alone.

\section{References}

1 Drobac M, Gilbert B, Howard R, Baigrie R, Rakowski H. Ventricular septal defect after myocardial infarction: diagnosis by two-dimensional contrast echocardiography. Circulation 1983;67:335-41.

2 Miyatake K, Okamoto M, Kinoshita N, et al. Doppler echocardiographic features of ventricular septal rupture in myocardial infarction. J Am Coll Cardiol 1985;5:182-7.

3 Eisenberg PR, Barzilai B, Perez JE. Non invasive detection by Doppler echocardiography of combined ventricular septal rupture and mitral regurgitation in acute myocardial infarction. J Am Coll Cardiol 1984;4:617-20.

4 Cheesman MG, John R, Murray N, Thomas J, Redding VJ. Pulsed Doppler ultrasound in the diagnosis of post-infarction ventricular septal defect [Abstract]. Br Heart J 1987;57:563. 